\title{
ÚLCERA CORNEAL BACTERIANA TRATADA CON ANTIBIÓTICO INTRAESTROMAL. MODELO EXPERIMENTAL IN VIVO
}

\section{BACTERIAL CORNEAL ULCER TREATED WITH INTRASTROMAL ANTIBIOTIC. EXPERIMENTAL MODEL IN VIVO}

\author{
STANGOGIANNIS-DRUYA E ${ }^{1}$, STANGOGIANNIS-DRUYA C ${ }^{2}$, NARANJO-TACKMAN R ${ }^{1}$, \\ VANZZINI V', VILLAR-KURÍ $\mathbf{J}^{1}$
}

\section{RESUMEN}

Objetivo: Estudio experimental in vivo con la finalidad de comparar la efectividad terapéutica de la administración intraestromal en dosis única diaria de gentamicina, tobramicina, ciprofloxacina y ofloxacina para el tratamiento de úlceras corneales por Pseudomonas aeruginosa.

Métodos: Se incluyeron 12 conejas blancas de Nueva Zelanda. Se les practicó desepitelización corneal central con hoja de bisturí No. 15 y se les aplicó una gota de cultivo Pseudomonas aerugino$s a$ en suspensión (75.000.000 unidades de colonias formadoras de bacterias). Todas las conejas recibieron antibioticoterapia a través de infiltración intraestromal. Se distribuyeron en cinco grupos según el antibiótico empleado: Grupo A: gentamicina, grupo B: tobramicina, grupo C: ciprofloxacina, grupo D: ofloxacina y grupos controles. A todos los ojos se les inyectó en el estroma corneal $0,3 \mathrm{mg} / \mathrm{ml}$ como dosis única antibiótica $(9 \mathrm{mcg} / 0,03 \mathrm{ml})$, iniciando la terapia entre las 48-72 horas a partir de la formación de la úlcera corneal. Para su control se tomaron diariamente fotografías clínicas digitales. A los siete días los ojos fueron enucleados y las córneas extraídas para su estudio histopatológico. \begin{abstract}
ginosa.
\end{abstract}
ABSTRACT

Objective: To compare the therapeutic effectiveness of a single intrastromal dose of gentamycin, tobramycin, ciprofloxacin and ofloxacin for the treatment of corneal ulcers due to Pseudomonas aeru-

Methods: Twelve white female New Zealand rabbits underwent mechanical removal of corneal epithelium; then one drop of salt suspension containing Pseudomonas aeruginosa $(75,000,000$ colony forming units) was instilled over the Bowman's layer. Rabbits were distributed in five groups according to the type of antibiotic used: group A: gentamycin, group B: tobramycin, group C: ciprofloxacin, group D: ofloxacin and control groups. A single intrastromal dose of antibiotic $(0.3 \mathrm{mg} / \mathrm{ml})$ was injected 48 to 72 hours post-inoculation. A clinical digital picture was taken daily for a week. Then rabbits were sacrificed, all the corneas were collected and a histopathologic study was performed.

Results: We observed a significant reduction of the size of the corneal ulcer in all groups $(F=8.861$; $\mathrm{p}=0.000)$. Rabbits treated with ciprofloxacin, had a significant reduction in the size of the ulcer (21.1 SD $5.7 \mathrm{~mm}^{2}$ ). The epithelial growth was slow and

\footnotetext{
Recibido: 22/9/06. Aceptado: 24/3/09.

Hospital Dr. Luis Sánchez Bulnes. Asociación Para Evitar la Ceguera en México, I.A.P. México, D.F. México.

${ }^{1}$ Licenciado en Medicina. Servicio de Córnea y Segmento Anterior.

2 Licenciado en Medicina. Centro Oftalmológico San Jorge (COSJ). Ciudad Bolívar. Venezuela.

${ }^{3}$ Licenciada en Química Farmacéutica Bióloga. Laboratorio de Microbiología.

Correspondencia:

Evangelia Stangogiannis Druya

Hospital Dr. Luis Sánchez Bulnes. Asociación Para Evitar la Ceguera en México, I.A.P.

Vicente García Torres \# 46, San Lucas, Coyoacán

04030 México, D.F.

México

E-mail: fesgod@hotmail.com / fesgod@gmail.com
} 
Resultados: Se observó disminución del tamaño de la úlcera en forma significativa en cada uno de los grupos estudiados $(F=8,861 ; p=0,000)$. Las conejas tratadas con ciprofloxacino, tuvieron una reducción más importante del tamaño de la úlcera $(21,1$ DE 5,7 $\mathrm{mm}^{2}$ ). La reepitelización corneal fue lenta y en ningún grupo se completó. El estudio histopatológico mostró ausencia de la membrana de Bowman. La concentración de los antibióticos utilizados en los grupos A, B y D no fue lo suficientemente efectiva para controlar la infección corneal por lo que ocasionó necrosis tisular.

Conclusión: El grupo C presentó mayor grado de epitelización, con incremento del número de queratocitos, así como infiltrado inflamatorio mixto, como resultado de la mayor efectividad terapéutica (CIM establecida $<1 \mathrm{mcg}$ ).

Palabras clave: Tratamiento intraestromal, antibióticos, úlcera corneal, Pseudomonas aeruginosa, microbiología. incomplete in all groups. The histopathologic study showed Bowman's layer absence. The antibiotic used was not effective in groups A, B and D for the control of the corneal ulcer showing tissular necrosis.

Conclusion: Group C showed greater degree of epithelization, with increased number of keratocites as well as inflammatory infiltrate as a result of greater therapeutic effectiveness (CIM $<1 \mathrm{mcg})$ (Arch Soc Esp Oftalmol 2009; 84: 123-132).

Key words: Intrastromal, antibiotic, corneal ulcer, Pseudomonas aeruginosa, microbiology.

\section{INTRODUCCIÓN}

El epitelio corneal por su naturaleza lipofílica y sus estrechas uniones con desmosomas intercelulares, actúa como una barrera inicial para la penetración de los fármacos y electrolitos hidrosolubles, lo que limita su absorción, por otro lado el estroma corneal por su naturaleza hidrófila actúa como una barrera para los fármacos en solventes lipídicos. Esto en ocasiones dificulta la acción de un medicamento en estroma corneal, por otro lado la falta de vasos sanguíneos en la córnea normal, impide que las substancias administradas por vía parenteral o subconjuntival alcancen fácilmente el estroma (1).

En la administración subconjuntival, la substancia llega a la córnea por la circulación perilímbica; por esta ruta el medicamento puede pasar a la cámara anterior por lo que su efecto terapéutico en el estroma decrece rápidamente (1).

Los aminoglucósidos penetran al interior de la bacteria para alcanzar su sitio de acción en el espacio periplásmico, esto se logra al atravesar sus paredes a través de los conductos acuosos formados por proteínas en donde sufren un proceso de transporte activo que requiere la presencia de oxígeno (2).

Las fluoroquinolonas de segunda generación (ciprofloxacina y ofloxacina) han demostrado ser efectivas en el tratamiento de infecciones oculares con una excelente actividad contra bacterias Gram positivas y negativas (3). La ciprofloxacina se absorbe en pequeñas cantidades después de su aplicación tópica y tiene acción bactericida como resultado de la interferencia con la enzima DNA-girasa necesaria para la síntesis del DNA bacteriano $(4,5)$. La ofloxacina es una droga bactericida de amplio espectro que actúa contra la mayoría de las bacterias Gram positivas y negativas, anaerobios y bacterias atípicas como: Chlamydia, Mycoplasma y Legionella (6).

Las infecciones corneales representan una amenaza tanto para el ojo como para la función visual. Por ello, nos propusimos investigar si la administración terapéutica intraestromal de gentamicina, tobramicina, ciprofloxacina y ofloxacina en dosis única y a una concentración adecuada podría ser útil en el tratamiento de la úlcera corneal por Pseudomonas aeruginosa, detener su progresión clínica y permitir su cicatrización.

\section{SUJETOS, MATERIAL, MÉTODOS}

Se trata de un estudio experimental, prospectivo in vivo, en donde se emplearon 12 conejas blancas de Nueva Zelanda con un peso entre 1.800 y 2.000 
g. Para su estudio fueron distribuidas en cuatro grupos de tres conejas cada uno (12 ojos). Para su clasificación se nominaron A, B, C y D. Se siguieron las pautas recomendadas por la Asociación para la Investigación en Visión y Oftalmología (ARVO) para el uso de animales en investigación oftalmológica.

\section{Estandarización del método de inoculación}

1. Preparación del inóculo: suspensión bacteriana en solución salina de un cultivo de 24 horas de incubación en medio de Meuller-Hinton en concentración de 75.000.000 bacterias por ml en solución salina de Pseudomonas aeruginosa recuperada de queratitis bacteriana humana.

2. Desepitelización mecánica con hoja de bisturí del No. 15, previa anestesia general con clorhidrato de ketamina (40 mg/kg) (Rotexmédica-GMBH, Alemania) y clorhidrato de xilazina $(7 \mathrm{mg} / \mathrm{kg})$ por vía intramuscular e instilación tópica de tetracaína $5 \mathrm{mg} / \mathrm{ml}$. Se realizó un marcaje circular del epitelio de la córnea con el uso de un trépano de 7,5 $\mathrm{mm}$ de diámetro, centrado en relación al limbo esclerocorneal. Se instilaron gotas de alcohol isopropílico al $70 \%$ en el interior del trépano en contacto con la córnea; después de 40 segundos se secó con el uso de esponjas de merocel, se retiró el trépano y se procedió a lavar con abundante solución isotónica de $\mathrm{Cl} \mathrm{Na} \mathrm{0,9 \%} \mathrm{estéril.} \mathrm{Inmediatamente} \mathrm{después} \mathrm{se}$ realizó la desepitelización mecánica en un área circunscrita a 7,5 mm correspondientes al tamaño del trépano y con la ayuda de una hoja de bisturí del No. 15.

Ambos ojos fueron intervenidos en forma simultánea; el ojo derecho de cada coneja fue utilizado como ojo estudio y el ojo izquierdo como control, al que se le infiltró únicamente solución salina isotónica $(\mathrm{Cl} \mathrm{Na} \mathrm{0,9 \% ).}$

3. Inoculación con Pseudomonas aeruginosa: se instiló en ambos ojos directamente sobre la capa de Bowman, una gota de la suspensión conteniendo a la bacteria.

4. Medición de la úlcera corneal: con este objetivo se tomaron diariamente y por siete días, fotografías de cada ojo de todas las conejas independientemente su grupo, utilizando una cámara digital Olympus ${ }^{\circledR}$ (modelo 3040-Z, Tokio, Japón) con resolución de 2048 x 1040 píxeles. Para obtener un contraste que delimitara el área afectada se tiñó el epitelio con fluoresceína sódica. Las fotografías obtenidas fueron estudiadas con el programa analizador de imágenes digitales (Scion Image ${ }^{\circledR}$, Friederich, MD). Se estandarizó la escala de medida en cada fotografía acorde a los 7,5 del área de desepitelización. La primera fotografía fue tomada inmediatamente después de practicar la inoculación bacteriana.

5. Identificación de los grupos de estudio: se inyectaron a nivel intraestromal cuatro tipos distintos de antibióticos. El medicamento fue aspirado en jeringas estériles de tuberculina identificadas con las letras de cada grupo. El investigador (ESD) a cargo de suministrar el tratamiento desconocía la sustancia asignada a cada grupo. Se inyectó una concentración de $0,3 \mathrm{mg} / \mathrm{ml}$ en dosis única de $0,3 \mathrm{ml}$; se estableció una concentración inhibitoria mínima (CIM) para cada uno de los antibióticos: gentamicina $<4$ mcgs, tobramicina $<4 \mathrm{mcg}$, ciprofloxacina $<1 \mathrm{mcg}$ y ofloxacina $<2 \mathrm{mcg}$. La terapia se inició entre las 48 y 72 horas posteriores a la inoculación. El antibiótico empleado en el grupo A fue gentamicina, en el grupo B tobramicina, en el grupo $\mathrm{C}$ ciprofloxacina y en el grupo $\mathrm{D}$ ofloxacina.

6. Análisis estadístico: los valores obtenidos fueron recolectados en una base de datos (Excel Microsoft Windows) y analizados con el programa estadístico (Stats Direct 1.9.7 para Windows, Ashwell, UK). Para el análisis de variables cuantitativas se realizó la descripción de la media y desviación estándar de cada grupo. Se utilizaron las pruebas de Anova y de Bonferroni para determinar diferencias de los grupos; el valor de significación se determinó con una $\mathrm{p} \leq 0,05$.

Los animales fueron sacrificados a los siete días de haber recibido el inóculo con una inyección intracardiaca de $3 \mathrm{cc}$ de tiopental sódico $1 \mathrm{~g} / 10 \mathrm{cc}$.

7. Estudio anatomopatológico: En todos los ojos se realizó disección del casquete corneoescleral a 3 $\mathrm{mm}$ del limbo y se fijó durante 24 horas en solución buffer de paraformaldehído al 10\%. Se realizó deshidratación de los tejidos con alcohol a concentraciones crecientes y se aclararon en xilol, después de lo cual se incluyeron en bloques de parafina que fueron cortados con microtomo en secciones de $3 \mu$. Posteriormente los cortes fueron desparafinados, colocados en portaobjetos y se procedió a su tinción con ácido peryódico de Schiff (PAS), hematoxilina y eosina (HE) y tinción tricrómica de Gomori para después proceder a la valoración histológica con un microscopio de luz (Nikon LABOPHOT-2 Japón). 


\section{RESULTADOS}

La valoración se llevó a cabo en forma cronológica estudiando y comparando las fotografías digi- talizadas que fueron realizadas desde el día cero (inoculación corneal), hasta el séptimo día después del tratamiento intraestromal; en ellas se observó que las úlceras corneales redujeron su tamaño de
A

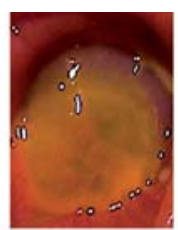

1

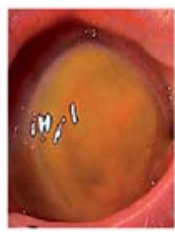

1

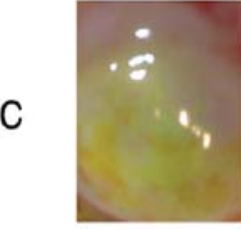

1

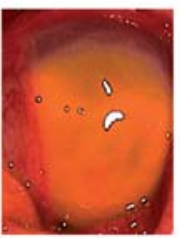

1

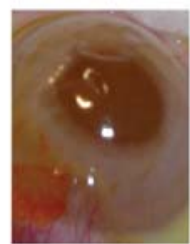

1

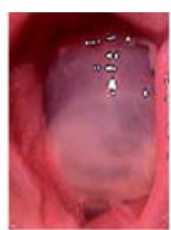

2

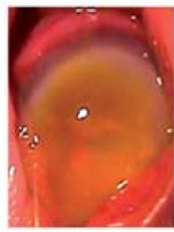

2

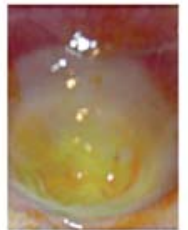

2

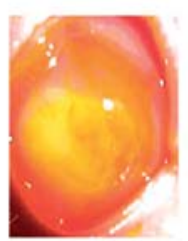

2

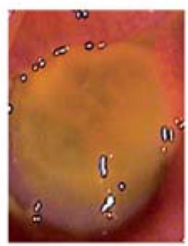

2

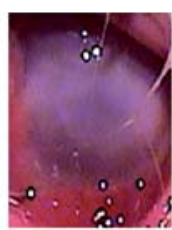

3

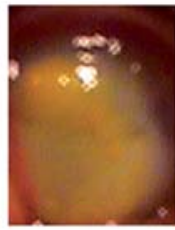

3

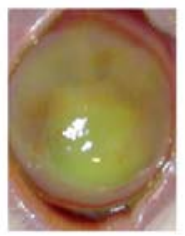

3

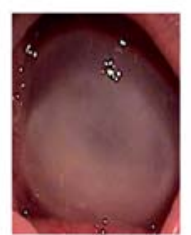

3

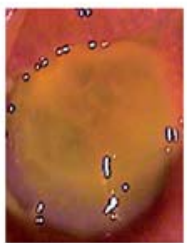

3

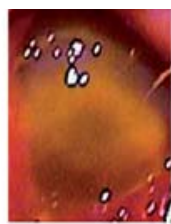

4

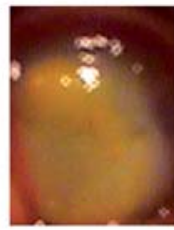

4

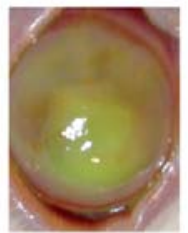

4

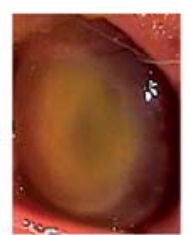

4

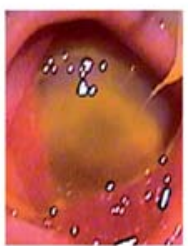

4

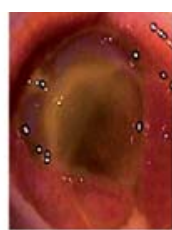

5

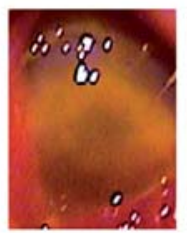

5

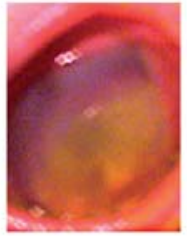

5

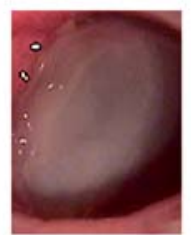

5

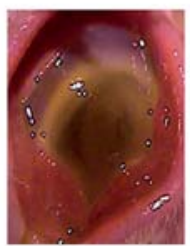

5

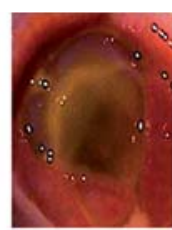

6

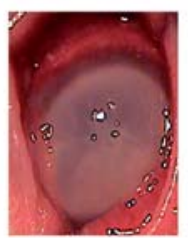

6

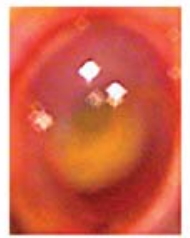

6

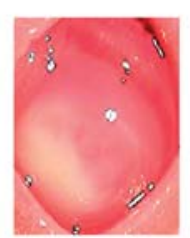

6

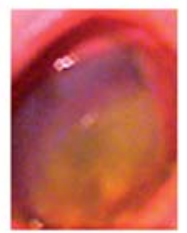

7

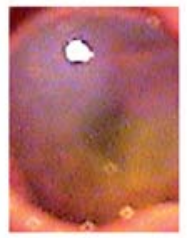

7

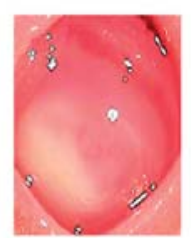

7

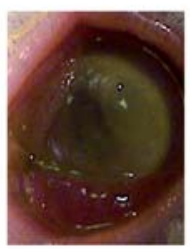

6

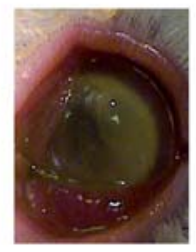

7

Fig. 1: Fotografías digitalizadas tomadas desde el día cero (abrasión corneal) hasta el séptimo día después del infiltrado del antibiótico intraestromal. 
manera diferente acorde al antibiótico infiltrado. (fig. 1).

La cicatrización de las úlceras tratadas con diferentes antibióticos, fue estadísticamente significativa al aplicar el análisis de comparaciones múltiples (F). En la tabla I, se observan las variaciones medias del área de defecto epitelial, mostrando disminución significativa del tamaño de la úlcera en cada uno de los grupos estudio $(\mathrm{F}=8,861 ; \mathrm{p}=0,000)$.

Las conejas que recibieron ciprofloxacina tuvieron una reducción mayor del tamaño de la úlcera, así mismo una reepitelización más rápida $(21,1 \mathrm{DE}$ $5,7 \mathrm{~mm}^{2}$ ) que las que recibieron otros antibióticos, sin que se pudiera conseguir en ninguna de ellas la cicatrización total. El resultado del tratamiento aplicado en cada uno de los grupos mostró diferencias estadísticamente significativas $\mathrm{F}=4,643$ $(\mathrm{p}=0,047)$. Los grupos control (tabla II), mostraron una progresión del tamaño de la úlcera corneal tanto en área, como en profundidad, con un marcado adelgazamiento, sin ser éste estadísticamente significativo $\mathrm{F}=12,885(\mathrm{p}=0,000)$.

En el estudio histopatológico del tejido corneal del grupo control se observó la presencia de epitelio esca- moso estratificado no queratinizado, con necrosis de las lamelas corneales superficiales e importante infiltrado inflamatorio de tipo mixto y eosinófilo; en el estroma posterior se apreció homogeneización tisular y necrosis extensa. La membrana de Descemet estuvo presente y ondulada, con material fibrinoleucocitario adosado a su superficie posterior, así como escasas células endoteliales en la periferia (fig. 2).

El grupo A (gentamicina) mostró epitelio cúbico estratificado en córnea periférica. Este epitelio desaparece en la porción central por la formación de una úlcera de forma irregular. El estroma se observó constituido por lamelas de tejido conectivo, homogeneizadas, infiltradas con células inflamatorias de tipo mixto (mononucleares y polimorfonucleares, neutrófilos y eosinófilos) y se observaron áreas de necrosis en los dos tercios anteriores de la córnea. En la periferia, se reconocen vasos sanguíneos congestivos e infiltrado inflamatorio adyacente al limbo. La membrana de Descemet se encontró ondulada, con escasas células endoteliales en su superficie posterior (fig. 3).

En el grupo B (tobramicina), el tejido corneal se observó tapizado por epitelio cúbico estratificado,

Tabla I. Tratamiento intraestromal sobre el área de defecto epitelial en $\mathbf{m m}^{2}$ posterior al trauma mecánico en las córneas de las conejas. Ojo problema

\begin{tabular}{|c|c|c|c|c|c|c|c|c|}
\hline \multicolumn{9}{|c|}{ Seguimiento (días) } \\
\hline Antibiótico & Basal & 1 & 2 & 3 & 4 & 5 & 6 & 7 \\
\hline Gentamicina & 39,9 DE 0,6 & 39,8 DE 0,7 & $39,8 \mathrm{DE} 1,5$ & $39,8 \mathrm{DE} 1,3$ & 39,8 DE 1,3 & $36,7 \mathrm{DE} 1,3$ & $39,2 \mathrm{DE} 1,7$ & $39,0 \mathrm{DE} 1,8$ \\
\hline Tobramicina & $40,2 \mathrm{DE} 3,8$ & $38,8 \mathrm{DE} 1,7$ & $38,3 \mathrm{DE} 1,4$ & $37,6 \mathrm{DE} 1,5$ & $37,4 \mathrm{DE} 1,4$ & $37,1 \mathrm{DE} 1,3$ & 36,9 DE 1,5 & $36,7 \mathrm{DE} 1,5$ \\
\hline Ciprofloxacina & $40,2 \mathrm{DE} 1,4$ & $39,9 \mathrm{DE} 1,5$ & 39,0 DE 1,4 & 35,2 DE 3,0 & $33,5 \mathrm{DE} 4,3$ & 27,4 DE 5,2 & 24,7 DE 6,5 & 21,1 DE 5,7 \\
\hline Ofloxacina & $40,1 \mathrm{DE} 1,8$ & 39,6 DE 1,3 & 39,5 DE 1,9 & $39,1 \mathrm{DE} 1,4$ & 39,1 DE 1,4 & $38,6 \mathrm{DE} 1,3$ & 37,0 DE 1,7 & 34,7 DE 2,9 \\
\hline
\end{tabular}

Valores expresados como media \pm desviación estándar (DE). Antibiótico: $\mathrm{F}=4,643$ ( $\mathrm{p}=0,047)$; Seguimiento: $\mathrm{F}=8,861$ ( $\mathrm{p}=0,000$ ); Prueba de Bonferroni post-hoc: Gentamicina vs Tobramicina: $p=1,000$; Gentamicina vs Ciprofloxacina: $p=0,086$

Gentamicina vs Ofloxacina: $\mathrm{p}=1,000$; Tobramicina vs Ciprofloxacina: $\mathrm{p}=0,346$; Tobramicina vs Ofloxacina: $\mathrm{p}=1,000$; Ofloxacina vs Ciprofloxacina: $\mathrm{p}=0,200$.

FUENTE: Instrumento de trabajo.

Tabla II. Tratamiento intraestromal sobre el área de defecto epitelial en $\mathbf{~ m m}^{2}$ posterior al trauma mecánico en las córneas de las conejas. Ojo control

\begin{tabular}{|c|c|c|c|c|c|c|c|c|}
\hline \multicolumn{9}{|c|}{ Seguimiento (días) } \\
\hline $\begin{array}{l}\text { Antibiótico } \\
\text { (control) }\end{array}$ & Basal & 1 & 2 & 3 & 4 & 5 & 6 & 7 \\
\hline Gentamicina & 30,0 DE 2,3 & $31,1 \mathrm{DE} 9,0$ & 34,0 DE 3,1 & $34,1 \mathrm{DE} 3,0$ & 35,0 DE 2,3 & 36,7 DE 1,8 & 39,4 DE 1,2 & 41,2 DE 1,5 \\
\hline Tobramicina & $29,9 \mathrm{DE} 1,6$ & $31,2 \mathrm{DE} 2,3$ & $34,0 \mathrm{DE} 3,1$ & $34,1 \mathrm{DE} 3,0$ & 35,0 DE 2,3 & $36,7 \mathrm{DE} 1,8$ & 39,9 DE 0,8 & $41,2 \mathrm{DE} 1,5$ \\
\hline Ciprofloxacina & 30,3 DE 2,1 & 31,2 DE 2,3 & $34,0 \mathrm{DE} 3,1$ & $34,1 \mathrm{DE} 3,0$ & 36,7 DE 2,3 & $36,9 \mathrm{DE} 2,4$ & 39,9 DE 0,8 & $40,6 \mathrm{DE} 1,4$ \\
\hline Ofloxacina & 30,3 DE 2,1 & 31,2 DE 2,3 & 34,0 DE 3,1 & 34,1 DE 3,0 & 35,0 DE 2,2 & 36,6 DE 1,9 & 39,9 DE 0,8 & 41,2 DE 1,5 \\
\hline
\end{tabular}

Valores expresados como media \pm desviación estándar (DE). Antibiótico: $\mathrm{F}=0,885$ ( $\mathrm{p}=0,930)$; Seguimiento: $\mathrm{F}=12,885$ ( $\mathrm{p}=0,000$ ).

FUENTE: Instrumento de trabajo. 


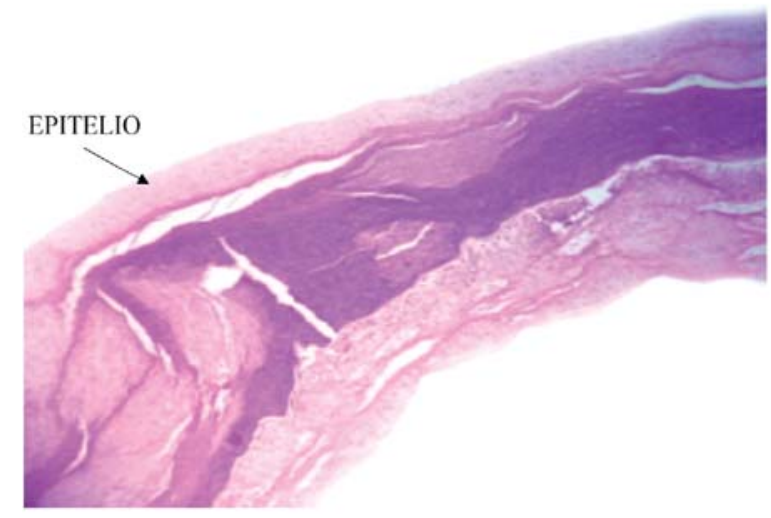

CASO 7634-05 Control. Corte histológico de córnea. Se observa el epitelio superficial, las lamelas corneales necróticas. Material fibrinoide e infiltrado inflamatorio adosado a la cara posterior de la Descemet. (H/E 40X)

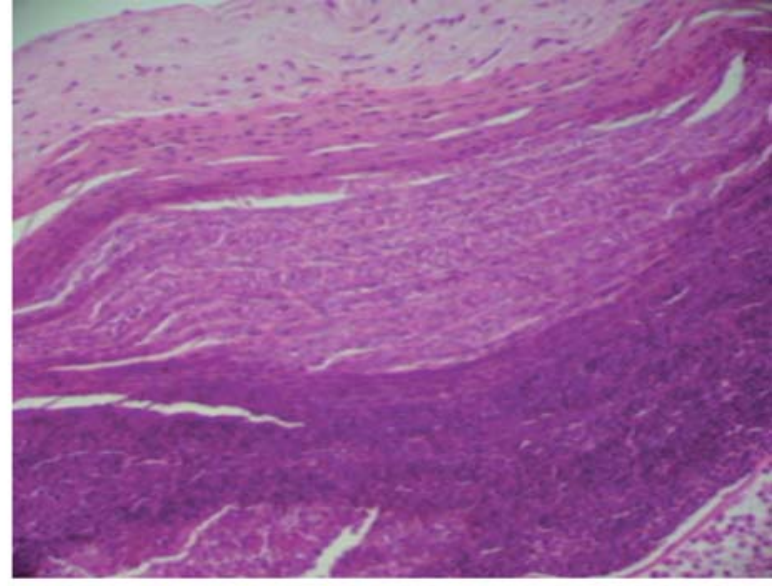

Control. A mayor aumento, el estroma superficial está conservado, posteriormente están las lamelas corneales necróticas, un segmento de membrana de Descemet e hipopion. (H/E 100X)

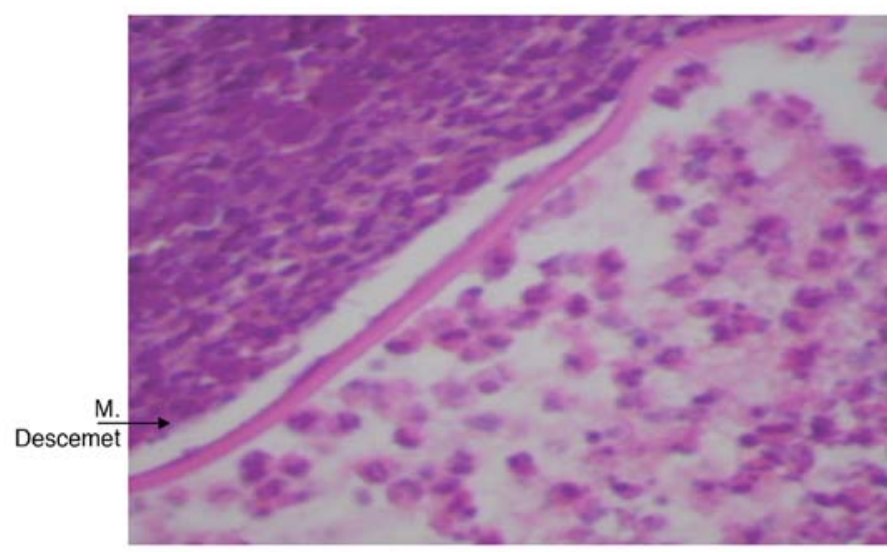

Control. Membrana de Descemet con los restos de estroma profundo. Infiltrado inflamatorio en la cara posterior (hipopion) (H/E 400X)

Fig. 2: Grupo control. Corte histológico que muestra en la periferia epitelio escamoso estratificado no queratinizado. En la porción central se evidencia una ulcera, con necrosis de las lamelas corneales superficiales y un importante infiltrado inflamatorio de tipo mixto con presencia de eosinófilos; en el estroma posterior se aprecia una homogeneización y necrosis extensa. La membrana de Descemet está presente, ondulada y con material fibrinoleucocitario adosado a su superficie posterior y con escasas células endoteliales en la periferia.

con áreas de necrosis en las capas superficiales del estroma, sus lamelas homogeneizadas y necróticas en su mayor parte e infiltradas por células polimorfonucleares, neutrófilos y abundantes eosinófilos. La membrana de Descemet desplegada mostrando un nódulo necrótico adosado a su superficie posterior, restos de fibrina e infiltrado inflamatorio polimorfonuclear, correspondiente a un absceso retrocorneal (fig. 4).
En el grupo C (ciprofloxacina), se evidenció una córnea tapizada por epitelio cúbico estratificado de espesor irregular, cuyas células epiteliales mostraron hipercromasia nuclear en las capas basales y la presencia de queratinización en la superficie corneal. El estroma compuesto por lamelas de disposición en paralelo, algunas homogeneizadas, con incremento en la cantidad de queratocitos y presencia de un infiltrado inflamatorio, predominantemente en 


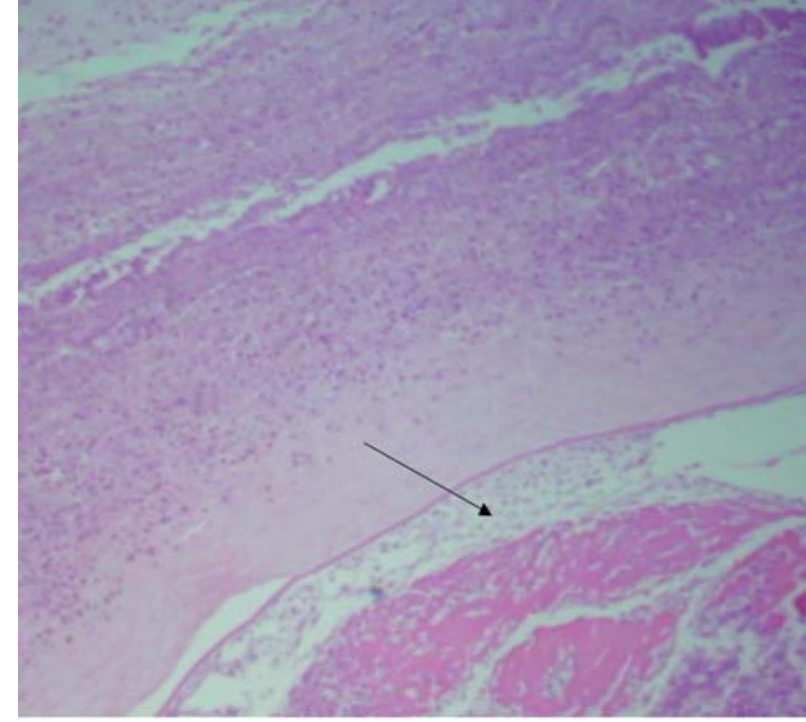

Caso 6572. Tobramicina. Infiltrado inflamatorio intenso en el estroma corneal. Absceso retrocorneal compuesto por fibrina, restos necróticos e infiltrado inflamatorio mixto (H/E 40X)

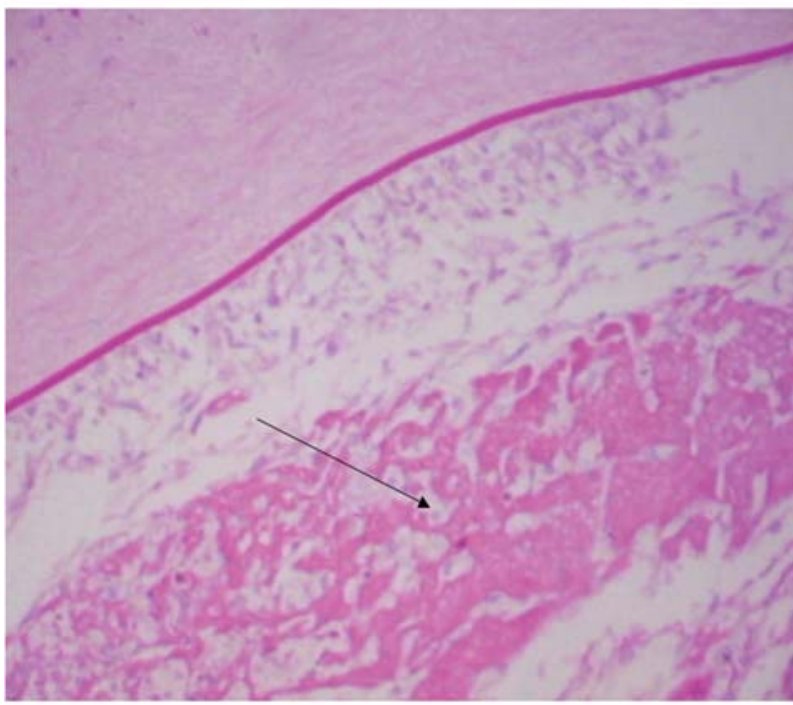

Tobramicina. Absceso retrocorneal (zona de tejido necrótico) (PAS 200X)

Fig. 3: Grupo A (gentamicina), Se observa epitelio cúbico estratificado en la córnea periférica. Este epitelio desaparece en la porción central con la formación de una úlcera de forma irregular. El estroma está compuesto por lamelas de tejido conectivo, homogeneizadas, infiltradas por células inflamatorias de tipo mixto, (mononucleares y polimorfonucleares, neutrófilos y eosinófilos) que producen necrosis en los dos tercios anteriores de la córnea. En la periferia, se reconocen vasos sanguíneos congestivos e infiltrado inflamatorio adyacentes al limbo. La membrana de Descemet se encuentra ondulada, con escasas células endoteliales en su superficie posterior.

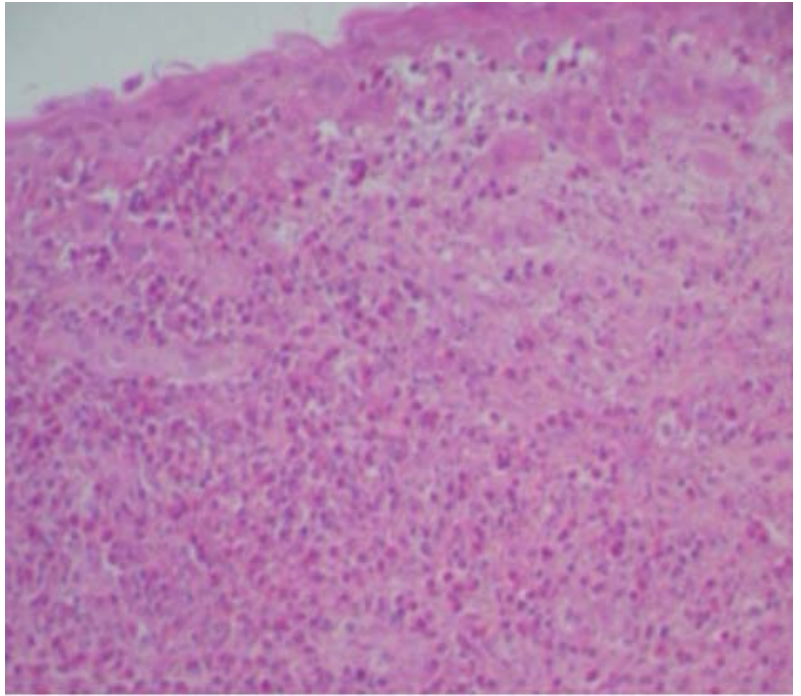

Caso 6570 Gentamicina. En la superficie se observan restos de epitelio de revestimiento. El estroma muestra intenso infiltrado inflamatorio mixto, a predominio de eosinófilos. (H/E 100X)

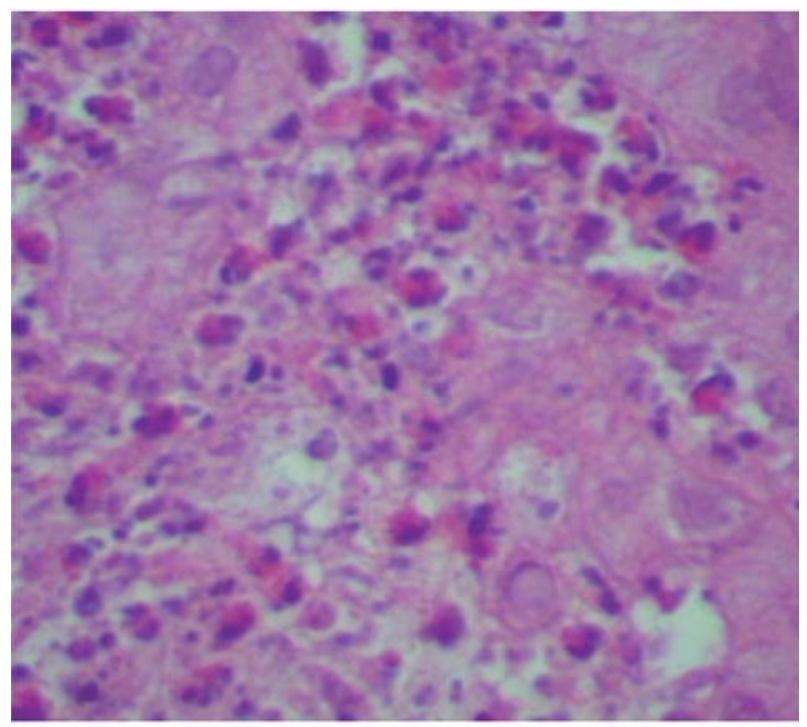

Gentamicina. Infiltrado inflamatorio compuesto casi exclusivamente por eosinófilos (H/E 400X)

Fig. 4: Grupo B (tobramicina). La córnea se encuentra tapizada por epitelio cúbico estratificado, así mismo muestra con necrosis de las capas superficiales del estroma, que está compuesto por lamelas homogeneizadas, necróticas en su mayor extensión e infiltradas por polimorfonucleares, neutrófilos y abundantes eosinófilos. La membrana de Descemet está plegada y presenta un nódulo necrótico adosado a su superficie posterior, restos de fibrina e infiltrado inflamatorio polimorfonuclear, compatible con un absceso retrocorneal. 


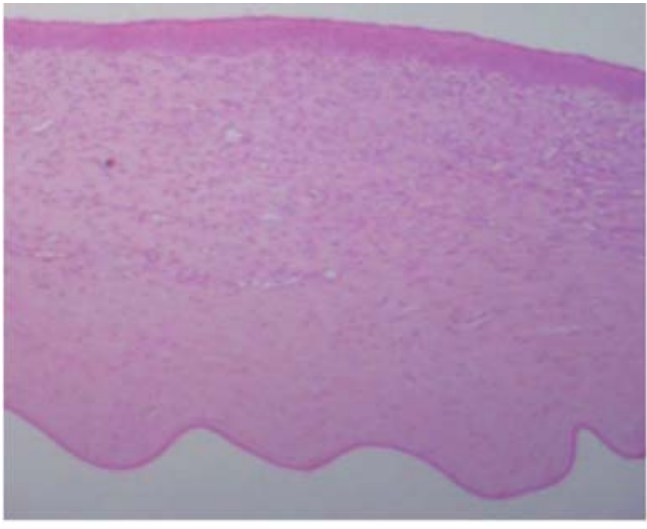

Caso 6569 Ciprofloxacina. Queratitis aguda: Epitelio conservado. Presencia de infiltrado inflamatorio en el estroma. Membrana de Descemet plegada (H/E 40X)

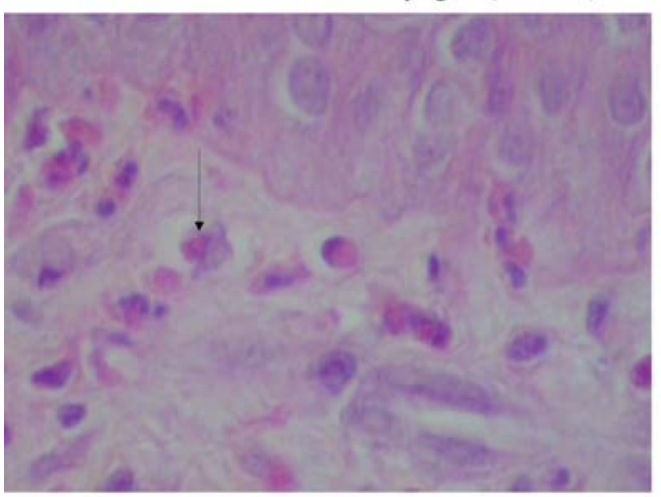

Ciprofloxacina. Infiltrado inflamatorio subepitelial, compuesto por polimorfonucleares cosinófilos (H/E 400X)

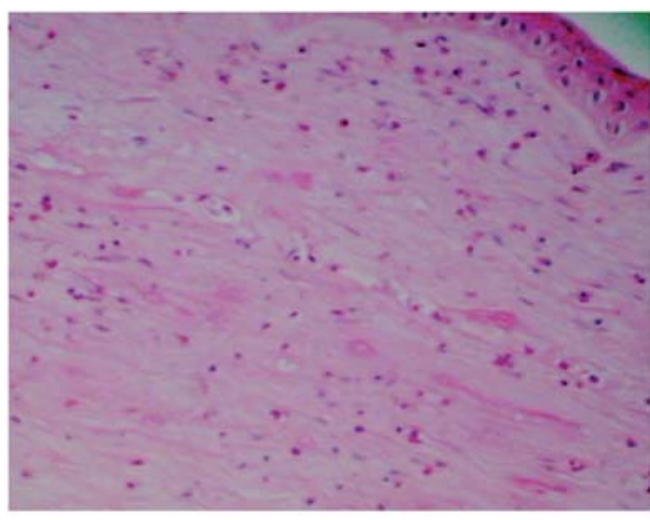

Ciprofloxacina. Queratitis aguda, presencia de células inflamatorias (linfocitos y polimorfonucleares en el estroma) $\mathrm{H} / \mathrm{E} 100 \mathrm{X}$

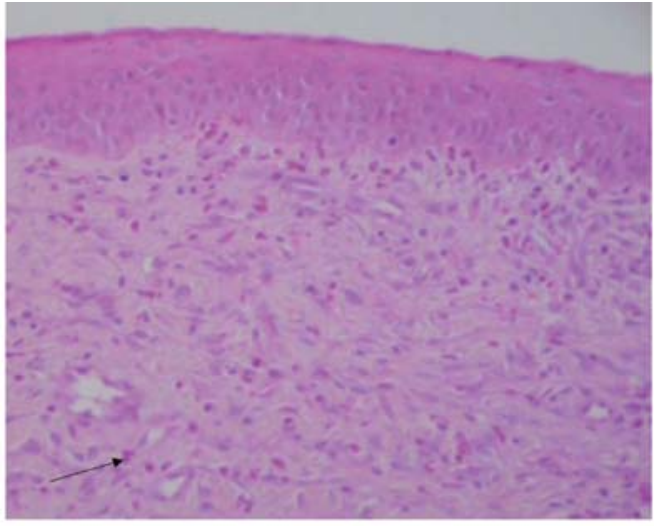

Ciprofloxacina. Abundante infiltrado inflamatorio de cosinófilos entre las lamelas corneales (H/E I00X)

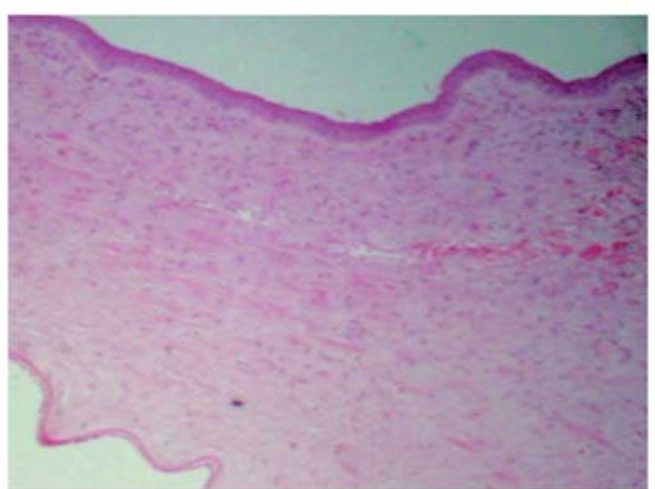

CASO 6571 Ciprofloxacina. Cómea plegada, con presencia de infiltrado inflamatorio y vasos sanguineos, cercanos al limbo. $(\mathrm{H} / \mathrm{E}$ 40X)

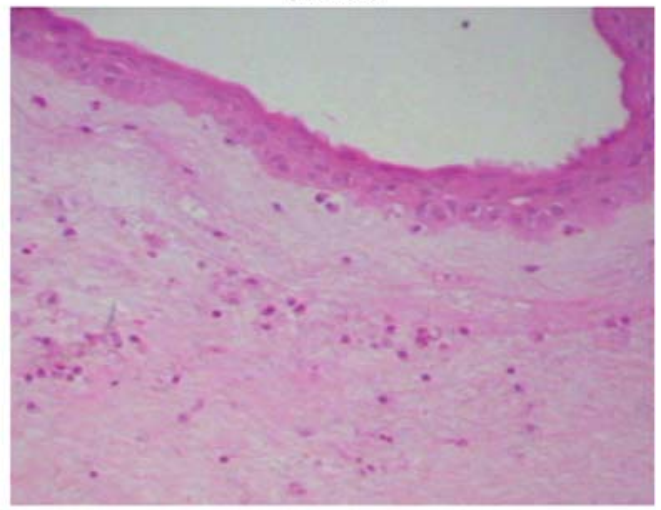

Ciprofloxacina. Epitelio reparativo. Infiltrado inflamatorio mixto, a predominio de eosinófilos en el estroma anterior. $(\mathrm{H} / \mathrm{E} 100 \mathrm{X})$

Fig. 5: Grupo C (ciprofloxacina). Se evidencia la córnea tapizada por epitelio cúbico estratificado de espesor irregular que тиеstra en las capas basales hipercromasia nuclear y la presencia de queratinización en la superficie. El estroma está compuesto por lamelas de disposición en paralelo, algunas homogeneizadas, con incremento en la cantidad de queratocitos y presencia de infiltrado inflamatorio con polimorfonucleares, neutrófilos y eosinófilos, predominantemente en los dos tercios anteriores. La membrana de Descemet se muestra plegada y tapizada en su superficie posterior con células endoteliales. En la periferia se observa epitelio plano estratificado con queratinización superficial focal; el estroma muestra abundantes vasos sanguíneos rodeados por un importante infiltrado inflamatorio de tipo polimorfonuclear, eosinófilo y de linfocitos típicos, con la tendencia a formar folículos linfoides. 
los dos tercios anteriores, con polimorfonucleares, neutrófilos y eosinófilos. La membrana de Descemet plegada y tapizada posteriormente con células endoteliales. En la periferia se observa epitelio plano estratificado con queratinización superficial focal, y el estroma mostró abundantes vasos sanguí- neos, rodeados por un importante infiltrado inflamatorio de tipo polimorfonuclear, eosinófilo y linfocitos típicos, con tendencia a formar folículos linfoides (fig. 5).

En el grupo D (ofloxacina), se evidenció un epitelio cúbico estratificado de espesor irregular. El

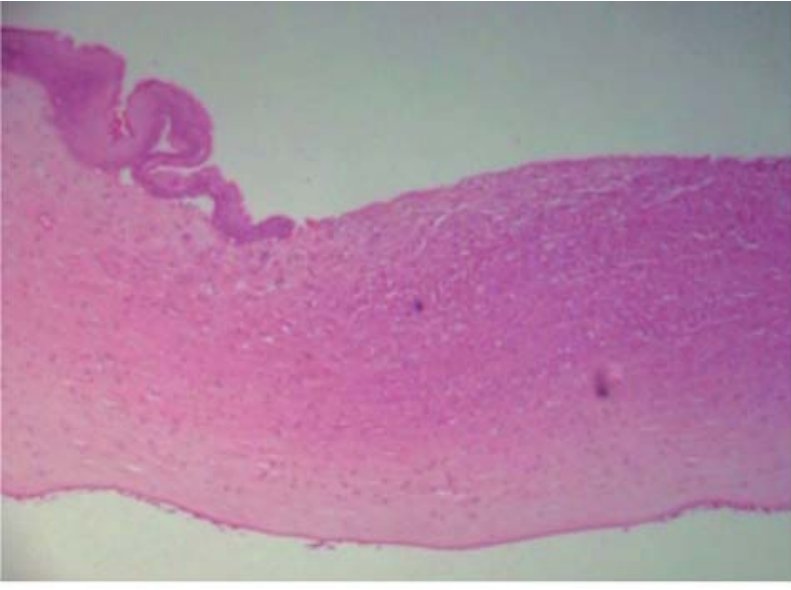

Caso 7636-05 Ofloxacina. Queratitis ulcerativa central, se reconocen restos de epitelio y el estroma subyacente con infiltrado inflamatorio (H/E $40 \mathrm{X})$

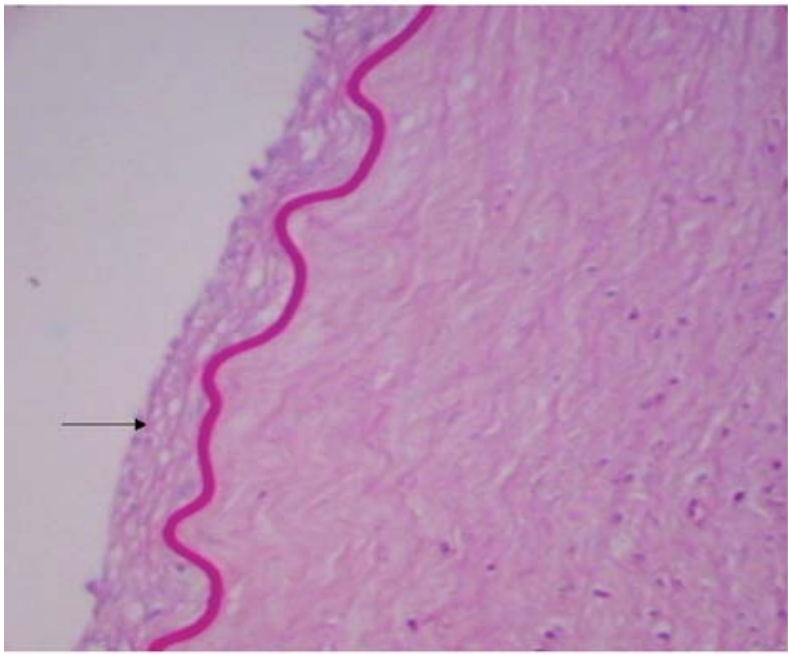

Ofloxacina. Membrana retrocorneal adherida a la membrana de Descemet (PAS 200X)

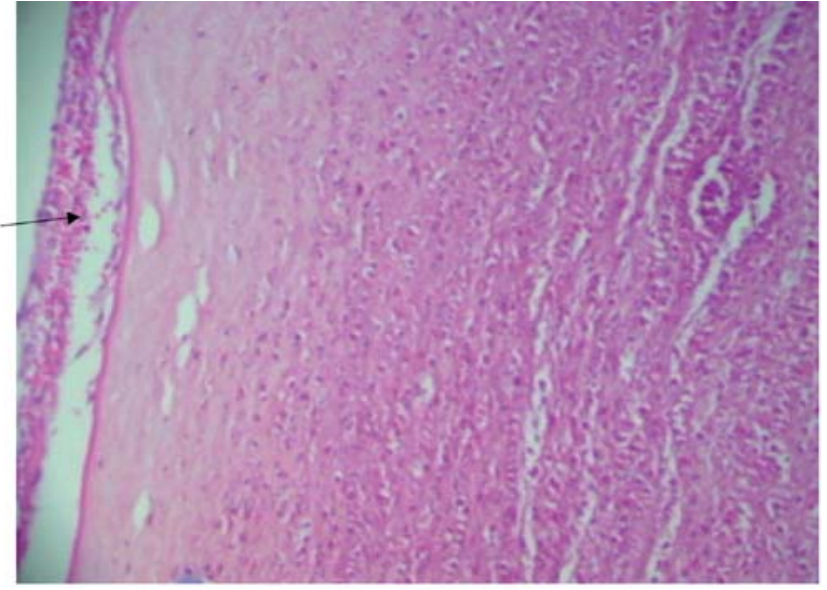

Ofloxacina. Estroma corneal con intenso infiltrado inflamatorio. Membrana retrocorneal. (H/E 100X)

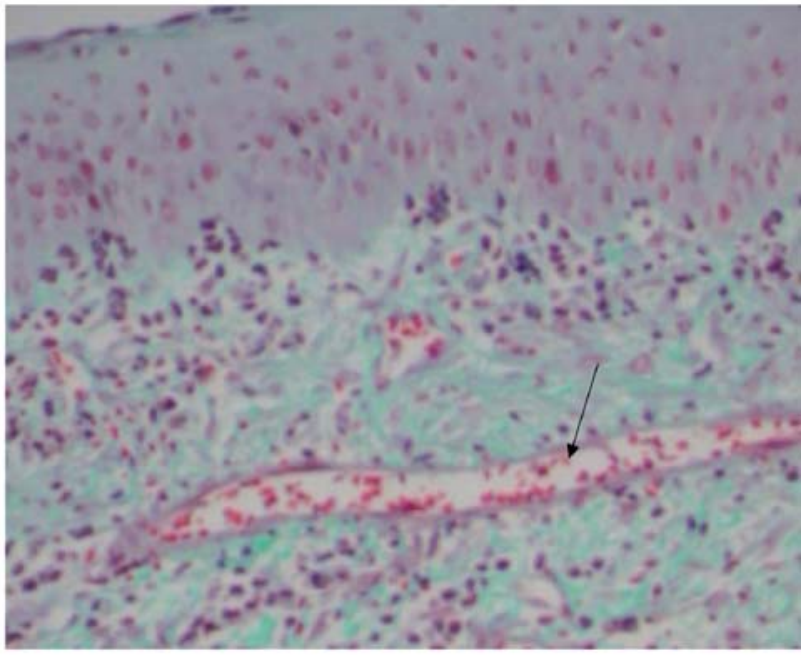

Ofloxacina. Epitelio acantótico de tipo reparativo. Leucoma vascularizado. Infiltrado inflamatorio en el estroma.

(Tricrómico de Gomori 100X)

Fig. 6: Grupo D (ofloxacina), se observa la presencia de un epitelio cúbico estratificado de espesor irregular, con la porción central de la córnea ulcerada. El estroma compactado muestra necrosis de las lamelas en los dos tercios anteriores e infiltración por células inflamatorias de tipo mixto. En la periferia se aprecian abundantes vasos sanguíneos dilatados y congestivos, algunos rodeados de infiltrado inflamatorio. La membrana de Descemet está ondulada, muestra escasas células endoteliales en su superficie posterior y una membrana retrocorneal en el centro. En la periferia se reconoce el limbo esclerocorneal con infiltrado inflamatorio estromal. 
estroma compactado mostró necrosis de las lamelas en los dos tercios anteriores e infiltración por células inflamatorias de tipo mixto. En la periferia se aprecian abundantes vasos sanguíneos dilatados y congestivos, algunos rodeados de infiltrado inflamatorio. La membrana de Descemet ondulada, mostrando escasas células endoteliales en su superficie posterior y membrana retrocorneal en el centro. En la periferia se reconoce el limbo esclercorneal con infiltrado inflamatorio en el estroma (fig. 6).

\section{DISCUSIÓN}

La vía de administración más común de los antibióticos oculares es la tópica, permite la saturación en la superficie ocular, en el estroma corneal y, al penetrar en la cámara anterior, logra una concentración inhibitoria mínima (CIM) adecuada; la penetración del antibiótico depende de sus cargas electrostáticas y su adhesividad a las proteínas presentes en el proceso inflamatorio (7).

Por otro lado, la aplicación de antibióticos en forma subconjuntival, permite que en la córnea se alcancen niveles elevados, pero por un período de tiempo de corta duración, alcanzando en 9 horas niveles máximos pero no terapéuticos (2).

El resultado del uso de esteroides de depósito con microinyecciones intraestromales en el tratamiento del rechazo corneal postqueratoplastia (8), ha demostrado la utilidad de esta forma de administración, que adquiere particular importancia, ante la posibilidad de usarla con otros medicamentos que, de otra manera, no alcanzan fácilmente los niveles terapéuticos a través de las vías de administración habituales.

Se ha propuesto el uso de fluoroquinolonas de cuarta generación para el tratamiento de la queratitis bacteriana acorde a sus resultados inhibitorios in vitro. Sin embargo, falta demostrarse su comportamiento in vivo $(9,10)$. En nuestro estudio en el que provocamos deliberadamente la formación de úlceras corneales por la instilación de suspensión conteniendo Pseudomonas aeruginosa, pudimos observar que las fluoroquinolonas de segunda generación por su capacidad bactericida, permiten una buena respuesta terapéutica en la cicatrización de la úlce- ra, observándose en el grupo C (ciprofloxacina) un incremento en la cantidad de queratocitos y la presencia de infiltrado inflamatorio mixto con una CIM establecida de $<1 \mathrm{mcg}$, dando la oportunidad que de manera más rápida cicatrizara la córnea sin que aún, a los siete días, lo hiciera en forma total. Estos antibióticos alcanzan una concentración inhibitoria mínima con baja toxicidad $(11,12)$.

\section{BIBLIOGRAFÍA}

1. Hyndiuk RA. Radioactive depot-corticosteroid penetration into monkey ocular tissue. II. Subconjunctival administration. Arch Ophthalmol 1969; 82: 259-263.

2. Kowalski RP, Karenchack LM, Romanowski EG. Infectious disease: changing antibiotic susceptibility. Opthalmol Clin North Am 2003; 16: 1-9.

3. O`Brien TP, Maquire MG, Fink NE, Alfonso E, Mc Donnell P. Efficacy of ofloxacin vs cefazolin and tobramycin in the therapy for bacterial keratitis. Report from the Bacterial Keratitis Study Research Group. Arch Ophthalmol 1995; 113: 1257-1265.

4. Seitz B, Torres F, Langenbucher A, Behrens A. Posterior corneal curvature changes after myopic laser in situ keratomileusis. Ophthalmology 2001; 108: 666-673.

5. Gordon RA, Donzis PB. Refractive development of the human eye. Arch Ophthalmol 1985; 103: 785-78.

6. Tungsiripat T, Sarayba MA, Kaufman MB, Sweet PM, Taban M, Carpenter TR, et al. Fluoroquinolone therapy in multiple-drug resistant syaphylococcal keratitis after lamellar keratectomy in a rabbit model. Am J Ophthalmol 2003; 136: 76-81.

7. Huang SC, Lai HC, Lai IC. The treatment of pseudomonas keratoscleritis after pterygium excision. Cornea 1999; 18: 608-611.

8. Arenas E, Navarro M, Mieth MA. Aplicación de corticoesteroides intracorneanos de depósito en el tratamiento de rechazo de queratoplastia. Arch Soc Esp Oftalmol 2004; 79: $75-79$.

9. Kowalski RP, Dhaliwal DK, Karenchack LM, Romanowski EG, Mah FS, Ritterband DC, et al. Gatifloxacin and moxifloxacin: an in vitro susceptibility comparison to levofloxacin, ciprofloxacin and ofloxacin using bacterial keratitis isolates. Am J Ophthalmol 2003; 136: 500-505.

10. Tungsiripat T, Sarayba MA, Kaufman MB, Sweet PM, Taban M, Carpenter TR, et al. Fluoroquinolone therapy in multiple-drug resistant staphylococcal keratitis after lamellar keratectomy in a rabbit model. Am J Ophthalmol 2003; 136:76-81.

11. Stahlmann R, Lode H. Toxicity of quinolones. Drugs 1999; 58: $37-42$.

12. Domagala JM. Structure-activity and structure side-effect relationships for the quinolone antibacterials. J Antimicrob Chemother 1994; 33: 685-706. 